\title{
HEAT TRANSFER THROUGH JOURNAL BEARING: A CASE STUDY
}

\author{
Peeyush Vats ${ }^{1}$, B.C. Sharma ${ }^{2}$, Sumit Sharma ${ }^{3}$ \\ ${ }^{1}$ Asso. Prof. Department of Mechanical Engineering, VIT Jaipur, Rajasthan, India \\ ${ }^{2}$ Professor. Department of Mechanical Engineering, BRCMCET, Bhiwani, Haryana, India \\ ${ }^{3}$ Asst. Prof. Department of Mechanical Engineering, VIT Jaipur, Rajasthan, India
}

\begin{abstract}
A journal bearing is designed for specific application. The bearing is designed according to the data available for the given bearing understudy. This analysis can usually be done with the advanced designed tool like FEA. This papers deal with the theoretical thermal analysis of a journal bearing by showing temperature distribution, heat generated and heat dissipated through the surfaces of the journal bearing. The tool used for FEM analysis on journal bearing is ANSYS.
\end{abstract}

Keywords: Journal bearing, Temperature distribution, Heat generation, FEA analysis.

\section{INTRODUCTION}

A journal bearing is a machine element which supports another moving machine element known as journal. One of the basic purposes of a bearing is to provide a frictionless environment to support and guide a rotating shaft. A good bearing material should be heat resistant, corrosion resistant. It should have good conformability, embedability. It should have high compressive strength to withstand high pressure. It should have proper endurance strength to avoid failure due to pitting. A Properly installed and maintained, journal bearing should have infinite life. It permits a relative motion between the contact surfaces of the members, while carrying the load with little loss of power due to friction. In order to reduce the frictional resistance and wear, and to carry away the heat generated, a layer of fluid which is known as lubricant has to provide to the bearing. The lubricant can be a gas, fluid, grease or solid of mineral oil, vegetable oil etc. Industrial machinery with a large horse power having high loads and speeds such as steam turbines, centrifugal pumps, compressors and motors, utilize journal bearing as rotor support. A bearing may fail in the improper load conditions, insufficient lubrication, contamination of lubricant, improper selection of bearing material; dust conditions, improper alignment etc.

It has been observed that the major breakdown occurs in the journal bearing of the turbine alternator of M/S Kaithal CoOperative Sugar Mills Ltd, Kaithal. In the power house of the Kaithal Co-Operative Sugar Mills Ltd, Kaithal, there was regular failure of power due to the reoccurrence failure of journal bearing of the multistage power turbine generator. The multistage steam turbine of $2500 \mathrm{~kW}$ is connected with reduction gear box $8325 / 1500 \mathrm{rpm}$. This reduction gear box is connected with generator by six bolt universal coupling. The opposite side of the rotor shaft of generator is supported by the journal bearing understudy (Fig 2). The journal bearing of the supporting side of the generator wears out frequently. The bearing of the supporting end of the generator is single oil lubricated, six tilting pad type pedestal journal bearing. This bearing is self contained having its design for taking its radial load and unbalanced magnetic pull of machine. The unit is electrically insulated from the ground to avoid excessive bearing current to flow through low resistance bearing pads and thus preventing pads from damage.

\section{LITERATURE REVIEW}

Literature review reveals that there are many causes of the bearing failures. The bearings are shown to fail due to unbalanced rotating forces, stress concentration in grooves provided for the passage of lubrication oil, thermal stresses caused due to differential coefficient of thermal expansions, insufficient oil supply to the interface, rapid wear rate due to the presence of mineral extraneous matter (MEM), propagation of internal cracks present due to the hot working of bearing steel, external loads, loads due to misalignment, seizure due to induced thermal stresses, excessive loads, temperature, speeds and the frequent start/stop operations etc. The numerous detection and analysis techniques employed for research work include ferrography, spectrometric oil analysis procedure (SOAP), accelerated life tests (ACT), optical microscopy and scanning electron microscopy (SEM), motor current signature analysis, neural networks and virtual sensors, finite element method (FEM) etc. Thus the literature review has provided an insight into possible reasons of bearing failure, various instruments/techniques for the detection of bearing failures and numerous analytical/computer tools which can be used for the study and analysis of the different types of bearings. Bonnett et al (1992) concluded that in recent years bearing failure have accounted for an increased percentage of motor failures. This is due in part to improved stator and rotor construction, which may result in the bearing to be the "weak link, Brown et al (1994) concluded that the behavior of non-linear systems often yields unexpected phenomena which are extremely sensitive to initial conditions. The hydrodynamic journal bearing is a common machine element which is strongly nonlinear for large excursions within the clearance space. Hodowanec (1996) observed that the $70 \%$ to $80 \%$ of motor field 
problems are mechanical in nature. A significant proportion of these mechanical problems which arise when external loads are exerted on bearings not designed to accommodate any extraneous loading. Din et al (1999) found that the study of friction and wear in a two grooved journal bearing at different shaft speeds, oil temperature and contamination levels. Awasthi et al (2007) concluded that a bearing subjected to frequent start/stop operations are worn progressively due to the rubbing. As a consequence, the geometry of the bearing changes and the performance is affected. Akagaki et al (1992) studied the failure process of a full-scale journal bearing, caused by insufficient oil supply to the interface, was monitored and analyzed with ferrography and the spectrometric oil analysis procedure (SOAP). Hazlett et al (1992) analyzed the details of a finite element model for the study of thermally induced stresses in journal bearing is presented. Rivas et al (2006) observed that the high wear rate on top roll shaft journals is an important problem for the Colombian sugar cane mill and it has shown a marked influence in the shaft reliability.

\section{METHODOLOGY}

There are some key areas which needed be considered and related to one another in order to analyze the journal bearing. The steps involved in the methodology are as

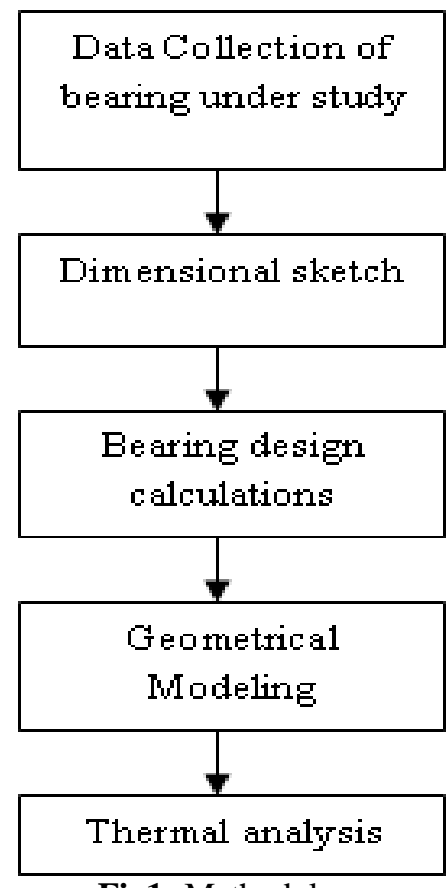

Fig1: Methodology

The adopted methodology will explain the thermal behavior of the bearing. In this methodology there will be a try to discuss the temperature distribution, heat generation and heat dissipation from the bearing understudy.

\subsection{Data Collection}

For thermal analysis of journal bearing it is compulsory to collect the data for the bearing understudy.

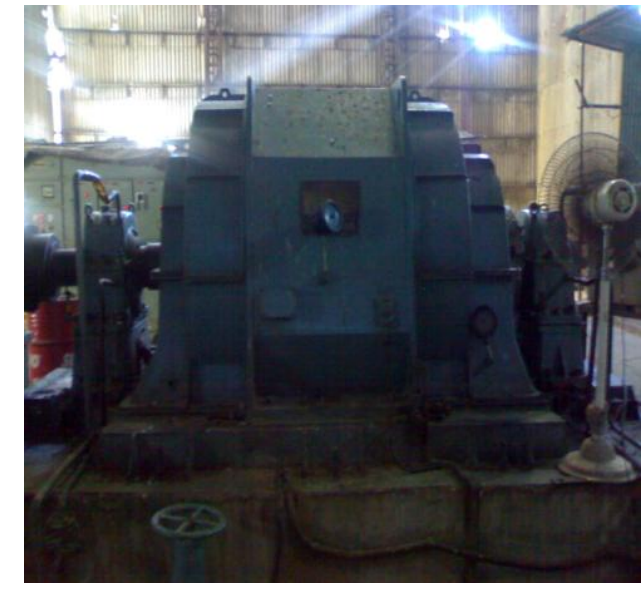

Fig 2: Location of bearing

The data is collected from the operating manual of the company. The unit in the company is shown in fig 2 The data obtained from the company is given below in Table 1 .

Table -1: Technical specification of Journal Bearing

\begin{tabular}{|l|l|l|}
\hline S. No. & Bearing Details & Values \\
\hline $\mathbf{1}$ & Revolution of journal & $1500 \mathrm{rpm}$ \\
\hline $\mathbf{2}$ & Applied load in KN & 2 to 10 \\
\hline $\mathbf{3}$ & Supply pressure & $140 \mathrm{KPa}$ \\
\hline $\mathbf{4}$ & Supply temperature & $50^{\circ} \mathrm{C}$ \\
\hline $\mathbf{5}$ & Bearing inner diameter & $200 \mathrm{~mm}$ \\
\hline $\mathbf{6}$ & Bearing outer diameter & $225 \mathrm{~mm}$ \\
\hline $\mathbf{7}$ & Bearing length & $240 \mathrm{~mm}$ \\
\hline $\mathbf{8}$ & Groove length & $70 \mathrm{~mm}$ \\
\hline $\mathbf{9}$ & Ambient temperature & $30^{\circ} \mathrm{C}$ \\
\hline $\mathbf{1 0}$ & Material of bearing case & Alloy steel \\
\hline $\mathbf{1 1}$ & Material of journal & Stainless steel \\
\hline $\mathbf{1 2}$ & Material of bearing & Babbited material \\
\hline $\mathbf{1 4}$ & Lubricant used & SAE 30. \\
\hline
\end{tabular}

\subsection{Bearing Design Calculations}

For the thermal analysis of the journal bearing some important design calculations are needed. Some of the important design calculations are as speed of shafts, bearing clearance, ratio of bearing diameter to the bearing clearance, bearing pressure, bearing characteristics and bearing modulus, coefficient of friction, load on the bearing, heat generated, heat dissipated and the difference between heat generated and heat dissipated. These bearing design calculations are tabulated as below: 
Table -1: Bearing Design calculations

\begin{tabular}{|c|c|c|c|}
\hline $\begin{array}{l}\text { Sr. } \\
\text { No. }\end{array}$ & $\begin{array}{l}\text { Bearing Design } \\
\text { Calculation }\end{array}$ & $\begin{array}{l}\text { Mathematical } \\
\text { expression }\end{array}$ & Value \\
\hline 1 & Speed of shaft & $\begin{array}{l}\mathrm{U}=\left(\begin{array}{llll}2 & \pi & \mathrm{r} & \mathrm{N}\end{array}\right) / \\
60\end{array}$ & $15.7 \mathrm{~m} / \mathrm{s}$ \\
\hline 2 & $\begin{array}{l}\text { Bearing } \\
\text { clearance }\end{array}$ & $\begin{array}{l}\mathrm{c}=(0.0005) \mathrm{x} \mathrm{d} \\
\mathrm{mm} \text { For Babbitt } \\
\text { material }\end{array}$ & 0.1 \\
\hline 3 & $\begin{array}{l}\text { Ratio of bearing } \\
\text { diameter to the } \\
\text { bearing } \\
\text { clearance }\end{array}$ & $\mathrm{d} / \mathrm{c}$ & 2000 \\
\hline 4 & Bearing pressure & $\begin{array}{l}\mathrm{p}=.0634^{3} \sqrt{\mathrm{V}} \text { in } \\
\text { S.I. units }\end{array}$ & $\begin{array}{ll}.158 & \mathrm{~N} / \\
\mathrm{m}^{2} & \end{array}$ \\
\hline 5 & $\begin{array}{l}\text { Bearing } \\
\text { characteristics }\end{array}$ & $\mu \mathrm{N} / \mathrm{p}$ & 151.8 \\
\hline 6 & $\begin{array}{l}\text { Coefficient of } \\
\text { friction }\end{array}$ & $\begin{array}{l}0.326(\mu \mathrm{N} / \mathrm{p}) \mathrm{x} \\
(\mathrm{d} / \mathrm{c})+\mathrm{k}, \quad \mathrm{k}= \\
.002\end{array}$ & .01197 \\
\hline 7 & $\begin{array}{l}\text { Load on the } \\
\text { bearing }\end{array}$ & $\mathrm{W}=\mathrm{p} \times(1 \times 2 \mathrm{r})$ & $\begin{array}{l}76209.6 \\
\mathrm{~N}\end{array}$ \\
\hline 8 & Heat generated & $Q_{g}=f \times W \times U$ & $\begin{array}{l}14328 \\
\text { Watts }\end{array}$ \\
\hline 9 & Heat dissipated & $\begin{array}{l}\mathrm{Q}_{\mathrm{d}}=\mathrm{h}_{\mathrm{CR}} \quad \mathrm{X} \quad \mathrm{A} \quad \mathrm{x} \\
\left(\mathrm{t}_{\mathrm{b}}-\mathrm{t}_{\mathrm{a}}\right)\end{array}$ & $\begin{array}{l}1921.92 \\
\text { Watts }\end{array}$ \\
\hline 10 & $\begin{array}{l}\text { Difference } \\
\text { between heat } \\
\text { generated and } \\
\text { heat dissipated }\end{array}$ & $Q_{g}-Q_{d}$ & $\begin{array}{l}12406.08 \\
\text { Watts }\end{array}$ \\
\hline
\end{tabular}

\subsection{Dimensional Sketch of Journal Bearing}

For the thermal analysis of the journal bearing it is compulsory to draw the dimensional sketch of the journal bearing. The two dimensional sketch of the journal bearing is drawn in Auto-Cad.

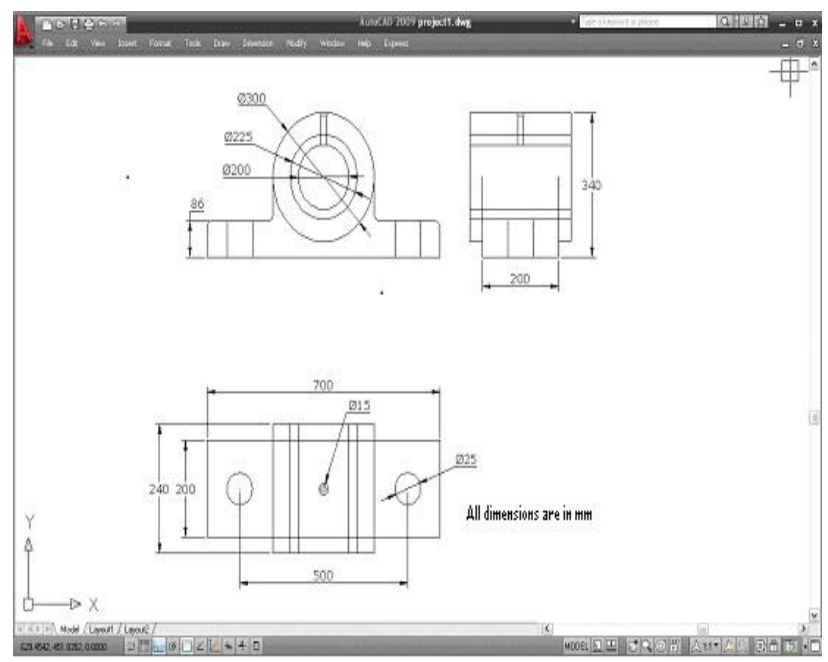

Fig 3: Dimensional Sketch

\subsection{Geometrical Modeling}

For the thermal analysis of the journal bearing the geometrical modeling of the bearing was prepared in Pro
Engineer wild fire 2.0 software with the help of dimensional sketch prepared in Auto CAD. Fig 4 shows the bearing casing, bearing and the journal in the assembled condition.

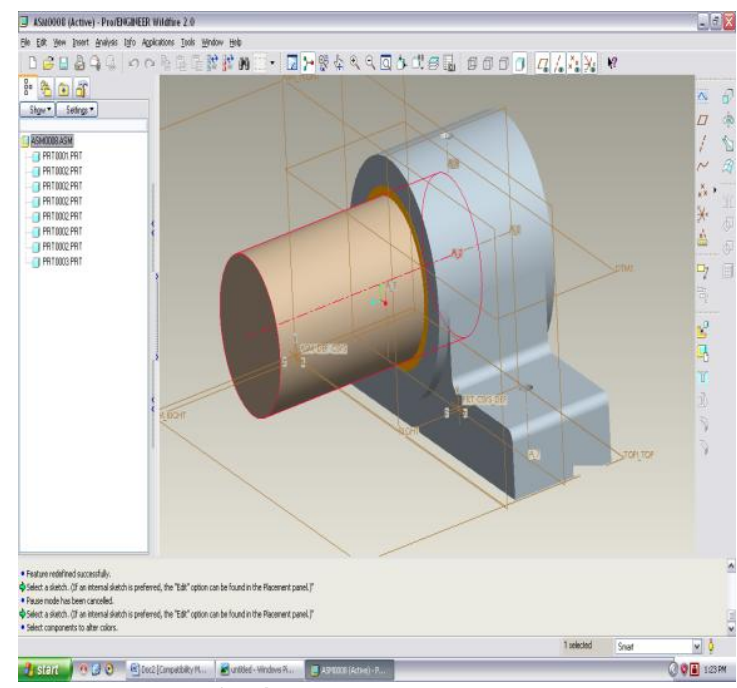

Fig 4: Geometrical model

\subsection{Thermal Analysis}

After preparing the dimensional sketch and geometric model of bearing, the model is imported from proE to ANSYS. The model is meshed for the thermal analysis of the journal bearing and Tetra 10 node 187 , element is used.

\subsubsection{Meshing of Journal Bearing}

Before meshing the model and even before building the model, it is important to think about whether a free mesh or a mapped mesh is appropriate for the analysis. A free mesh has no restrictions in terms of element shapes and has no specified pattern applied to it.

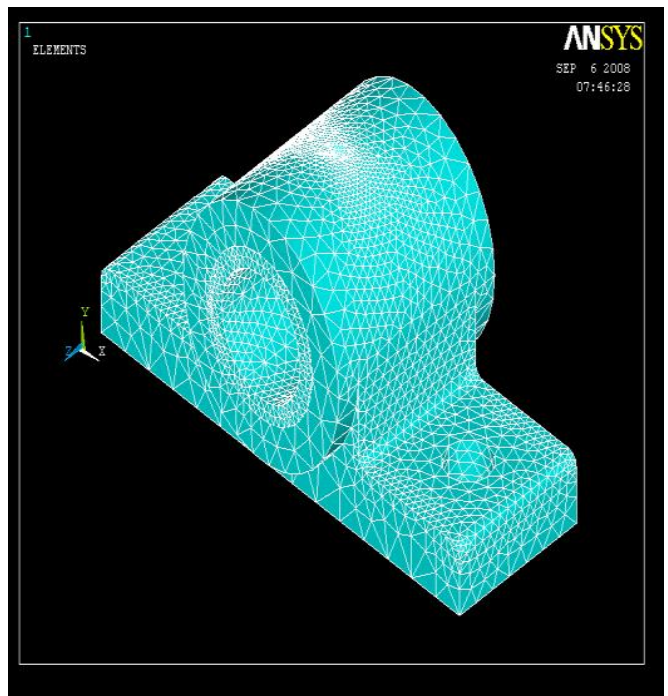

Fig 5: Meshing

A mapped mesh is restricted in terms of the element shape it contains and the pattern of the mesh. A mapped area mesh contains either only quadrilateral or only triangular elements, while a mapped volume mesh contains only 
hexahedron elements. In addition, a mapped mesh typically has a regular pattern, with obvious rows of elements. A mesh must be building the geometry as a series of fairly regular volumes and/or areas that can accept a mapped mesh.

\subsubsection{Convectional Area in a Journal Bearing}

Convection is heat transfer by mass motion of a fluid such as air or water when the heated fluid is caused to move away from the source of heat, carrying energy with it.

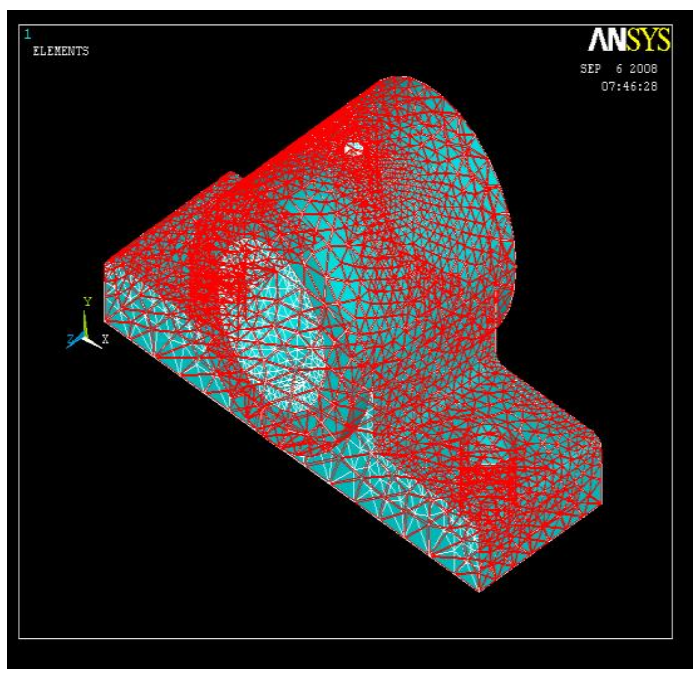

Fig 6: Convectional area of journal bearing

Convections are surface loads applied on exterior surfaces of the model to account for heat lost to (or gained from) a surrounding fluid medium. They are available only for solids and shells.

\subsubsection{Temperature Distribution in Journal Bearing:}

The temperature distribution across the element boundaries for the selected nodes and elements of the mesh is depicted with the help of color contour as shown in Fig 7.

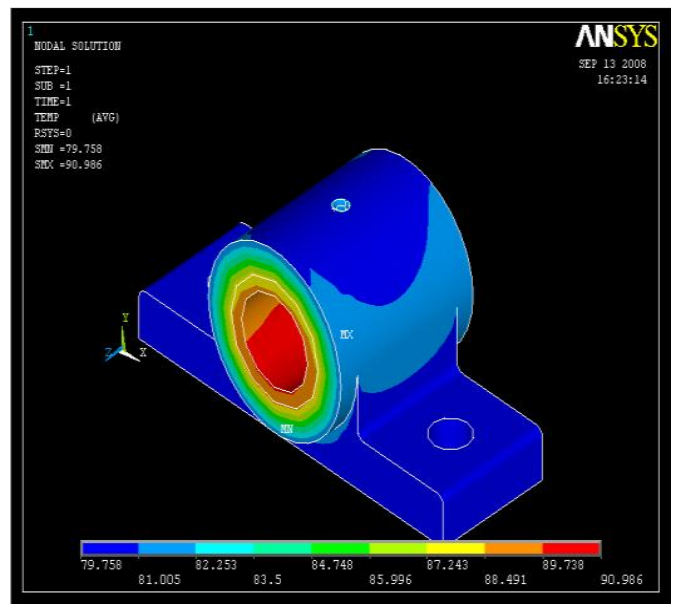

Fig 7: Temperature Distribution

Blue color shows the minimum value and the red color shows maximum value of the bearing temperature. Different color lies between blue and red color shows the intermediate values of the temperatures between maximum and minimum temperatures. In this case, maximum value of temperature is $90.96{ }^{\circ} \mathrm{C}$ and the minimum value of the temperature is $79.76{ }^{\circ} \mathrm{C}$.

\subsubsection{Heat Generation in Journal Bearing:}

Heat generation has critical influence on bearing material. To some extent, it can increase bearing pads wear and then reduce bearing life, give rise to thermal deformation.

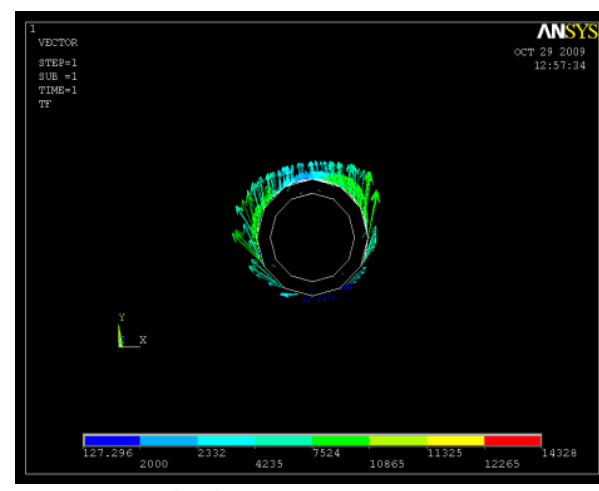

Fig 8: Heat generation

But due to the complexity of mechanism of journal bearing, it is hard to predict the intensity and distribution of the heat sources in an individual bearing.

It is assumed that the complete heat is generated in the in bearing which is made of Babbitt material. The maximum heat generated is 14328 Watts. The maximum heat generated and the minimum heat generated shown by the software is 14328 Watts and 127 Watts in the bearing, as shown in Fig 8. This heat generated has the tendency to flow out from the bearing through the material of the bearing. The direction of flow of heat generation is shown by the vectors.

\subsubsection{Heat Dissipation in Journal Bearing:}

It is assumed that the heat is dissipated from the upper half of the bearing case. The heat will be dissipated by convection from this portion. Bearing design calculation shows that the heat dissipated is 1921.92 Watts. The result obtained from the color contour of heat dissipation shows that the minimum value of heat dissipated value is 195.72 Watts and the maximum value of heat dissipated is 1932 Watts. The color contour of heat dissipated is shown in Fig 9. 


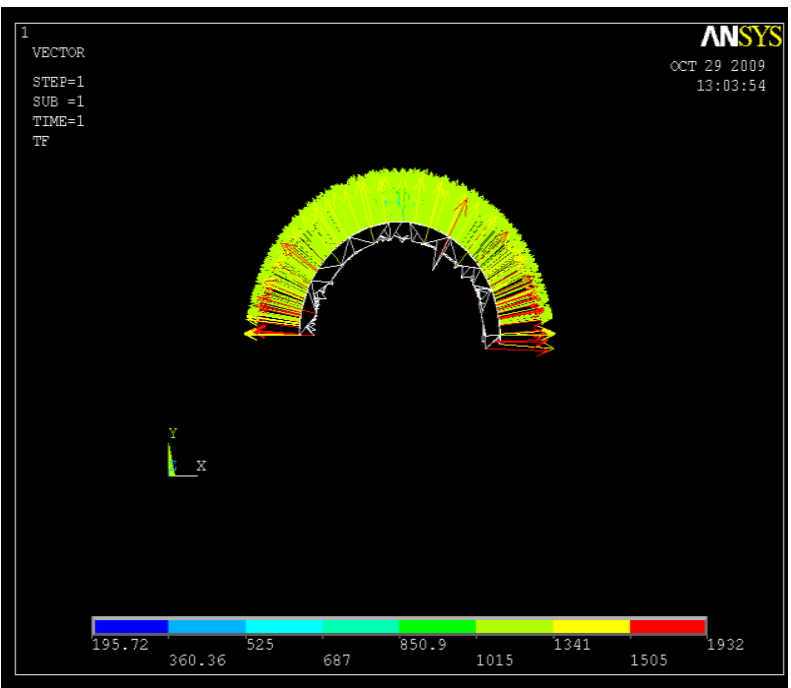

Fig 9: Heat dissipation

The red color vectors shown in Fig 9 indicate that the heat dissipation is maximum at these points. The cooling water entering to the bearing case takes some times to lift up at the inlet end of bearing case i.e. the heat dissipation is maximum at these points. Similarly, cooling water takes some time for ejecting at the outlet end of the bearing. The red color vectors are also present in this region. Hence the red heat dissipation maximum at outlet ends of the casing. There are only few vectors showing the heat dissipation of 1932 Watts.

Most of the vectors of heat dissipation are shown by yellow color. Yellow color shows the range of heat dissipation from 1341 Watts to 1505 Watts i.e. heat is dissipated from the surface of the bearing case at the rate of 1341 Watts to 1505 Watts. The heat dissipation showed the heat radially going outward. If there is a thermal equilibrium between heat generated and heat radiated, from the surface of the bearing, it will safe for the bearing.

\section{RESULT AND DISCUSSION}

On the basis of thermal analysis of journal bearing following results come in to the picture

\subsection{Temperature Distribution}

Fig 7 shows that the minimum temperature of the bearing is equal to $79.76{ }^{\circ} \mathrm{C}$ and the maximum value of the bearing temperature is equal to $90.99{ }^{\circ} \mathrm{C}$. The intermediate values of the temperature on the surface of the bearing are 79.758, $81.005,82.253,83.5,84.748,85.996,87.243,88.491$, 89.738 and $90.986{ }^{\circ} \mathrm{C}$ from blue to red color according to color contour.

\subsection{Heat Generation in Bearing}

Heat generated in the bearing was 14328 Watts. This heat was generated in the oil film. The oil is circulated between the bearing and the circular shaft of rotor which is called as journal. There acts a frictional force between the journal and the layer of the fluid. If the layer of the lubricating oil is sufficiently thick there is less heat generated, where there is a very thin film of the lubricating oil between the shaft and the lubricating oil, there are the chances of metal to metal contact and hence the maximum heat is generated in the oil film in that place. The maximum value of heat generation was 14328 Watts.

\subsection{Heat Dissipation from Bearing}

Fig 9 shows the heat dissipation from the upper half surface of the bearing. The minimum value of the heat dissipation is 195.72 Watts. The maximum value of the heat dissipation is 1932 Watts. The calculated value of the heat dissipation is 1921.92 Watts which is nearly equal to 1932 Watts. The other values of heat dissipation 360.36, 525, 687, 850.9, 1015, 1341, 1505 Watts lies between these values.

\section{CONCLUSIONS}

From the thermal analysis done above, the conclusions are drawn are as follows:

1. The calculated amount of the heat generated in the oil film of the bearing was 14328 Watts and the heat dissipated was 1921.92 Watts. The difference between heat generated in oil film and the heat dissipated from the surface of the bearing was 12406 Watts which is of was very large amount. Due to this heat, the bearing is warming up and the bearing pads are getting damaged.

2. The maximum and minimum temperature of the bearing were $90.98 \mathrm{C} \& 79.8 \mathrm{C}$ respectively.

\section{REFERENCES}

[1]. Austin H. Bonnett and Fellow, "Cause and Analysis of Bearing Failures in Electrical Motors", IEEE, 1992, pp 8795.

[2]. R.D.Brown, P.Addison and A.H.C.Chan,"Chaos in the Unbalance Response of Journal Bearings", Nonlinear Dynamics, 1994, pp 421-432.

[3]. Mark M.Hodowanec, "External Loading and Bearing Problems in Direct Connect Motors", IEEE, 1996, pp 153162.

[4]. R.K.Awasthi, Satish C Sharma and S.C. Jain, "Effect of Wear on the Performance of Non-Recessed Orifice Compensated Hybrid Journal Bearing", Tribology Transactions, Volume50, June2007, pp 361-373.

[5]. T.Akagaki and K.Kato, "Ferrographic Analysis of Failure Process in Full-Scale Journal Bearing", Wear152, 1992, pp 241-252.

[6]. T.L.Hazlett and M.M. Khonsari, "Finite Element Model of Journal Bearings Undergoing Rapid Thermally Induced Seizure", Tribology International, Volume25, No.3, 1992, pp 177-182.

[7]. Marc Carpino, Jih-Ping Peng and Lynn, "Misalignment in a Complete Shell Gas Foil Journal Bearing", Tribology Transactions, Volume 37, October 1994, pp 829-835

[8]. Sarath Jayatilleka and O. Geoffrey Okogbaa, "Accelerated Life Test For Identifying Potential Failure Modes And Optimizing Critical Design Parameters In A 
Journal Bearing", Proceedings annual reliability and maintainability symposium, IEEE, 2001, pp 70-74.

[9]. J.S.Rivas, J.J.Coronado and A.L.Gomez, "Tribological Aspects for the Shafts and Bearings of Sugar Cane Mills", Wear, Volume 261, 2006, pp 779-784.

[10]. Kaptan Teotrakool, Michael J.Devaney and Levent Eren,"Adjustable Speed Drive Bearing Fault Detection via Wavelet Packet Decomposition", Instrumentation and Measurement Technology Conference, IEEE, 2006, pp 2225 .

\section{BIOGRAPHIES}

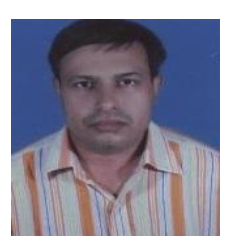

Peeyush vats did his BE (Mechanical Engg) in year 2001. He completed his ME in Manufacturing Technology from NITTTR Chandigarh affiliated to Panjab Univ Chandigarh. Now he is pursuing $\mathrm{PhD}$ from MNIT Jaipur in Industrial Engg. He has total 13 years of teaching Experience. He has published 2 papers in National conference.

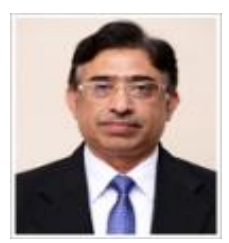

Dr. B.C. Sharma is Professor of Mechanical Engineering at BRCM College of Engineering \& Technology, Haryana. He received his $\mathrm{Ph} . \mathrm{D}$ degree in 2005 from IIT Delhi. He has 30 Reasearch Publications and 26 years teaching \& research experience including reliability engg., maintenance management \& safety evalution.

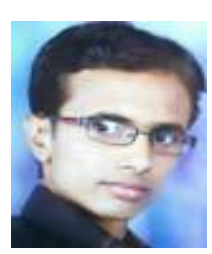

Sumit Sharma is Asst. Prof. Dept. of Mechanical Engineering in Vivekananda Institute of Technology, Jaipur. He has done his B.E. in Mechanical Engineering from Univ. of Raj. in 2008 and M.Tech (Thermal Engg.) from Raj. Tech. Univ. He has published two International Journal research papers in field of Mechanical Engineering. He has authored two books on Material Science \& Engineering and Computer Aided Design. 